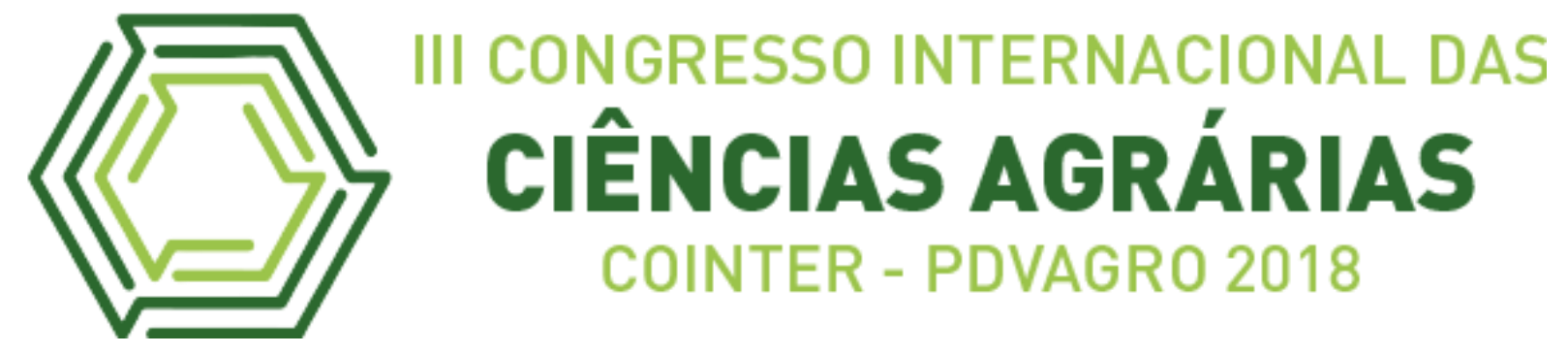

\title{
AÇÕES DE ASSISTÊNCIA TÉCNICA E EXTENSÃO RURAL EM COMUNIDADES RURAIS DE LAGOA DE ITAENGA, PERNAMBUCO
}

\section{ACTIVITIES OF TECHNICAL ASSISTANCE AND RURAL EXTENSION IN RURAL COMMUNITIES OF LAGOA DE ITAENGA, PERNAMBUCO}

\author{
Apresentação: Relato de Experiência
}

Paulo Henrique Oliveira Carmo ${ }^{1}$; Maciel Alves Tavares ${ }^{2}$; Bruno Wallace do Carmo Perônico ${ }^{3}$; José Miguel da Silva Neto ${ }^{4}$; Wellington Costa da Silva ${ }^{5}$

DOI: https://doi.org/10.31692/2526-7701.IIICOINTERPDVAGRO.2018.00703

\section{Introdução}

A Assistência Técnica e Extensão Rural (ATER) têm como objetivo principal prestar suporte técnico através da realização de acompanhamento das atividades desenvolvidas pelos agricultores e agricultoras familiares. Esse acompanhamento visa melhorarasua qualidade de vida nas comunidades através da proposição de técnicas paraaumento da eficiência no sistema produtivo.

Nesse sentido, as comunidades juntamente com Instituto Federal de Pernambuco Campus Vitória de Santo Antão desenvolveram atividades de extensão com o intuito de construir e também compartilhar com a comunidade, algumas práticas que pudessem auxiliar a comunidade a reduzir os impactos de sua principal problemática, a escassez hídrica.

\footnotetext{
${ }^{1}$ Bacharelado em Agronomia, Instituto Federal de Educação Ciência e Tecnologia de Pernambuco - Campus Vitória de Santo Antão, paulinho.mb.1997@hotmail.com

${ }^{2}$ Bacharelado em Agronomia, Instituto Federal de Educação Ciência e Tecnologia de Pernambuco - Campus Vitória de Santo Antão, macieltavares15@gmail.com

${ }^{3}$ Bacharelado em Agronomia, Instituto Federal de Educação Ciência e Tecnologia de Pernambuco - Campus Vitória de Santo Antão, brunowperonico1@gmail.com

${ }^{4}$ Bacharelado em Agronomia, Instituto Federal de Educação Ciência e Tecnologia de Pernambuco - Campus Vitória de Santo Antão,josemiguelifpe@gmail.com

${ }^{5}$ Professor Doutor, Instituto Federal de Educação Ciência e Tecnologia de Pernambuco - Campus Vitória de Santo Antão, welligton.costa@ vitoria.ifpe.edu.br
} 


\section{Relato de Experiência}

O presente trabalho foi realizado no período de janeiro a dezembro de 2017, nas Comunidades de Imbé, Marrecos e Sítios Vizinhos, no município de Lagoa de Itaenga, zona da mata de Pernambuco.

Durante este período realizamos ações de Assistência Técnica e Extensão Rural (ATER), com o intuito de construir conhecimentos e discutir estratégiaspara melhoria da qualidade de vida dos agricultores e agricultoras familiares de base agroecológica.

Atualmente, a agricultura apresenta uma importância indiscutível para a vida dos seres humanos, porém ela causa impactos sociais e ambientais, tais como: exclusão social, redução de biodiversidade, contaminação de cursos hídricos e etc. Nesse sentido, as comunidades juntamente com Instituto Federal de Pernambuco - Campus Vitória de Santo Antão desenvolveramatividades de extensão com o intuito de construir e também compartilhar com a comunidade, algumas práticas que pudessem auxiliar a comunidade a reduziros impactos de sua principal problemática, a escassez hídrica.

Devido às baixas taxas pluviométricas dos últimos anos, as comunidades estavam com sérias restrições de uso de água para irrigação das plantações. Por se trabalhar principalmente com produção de hortaliças, em sistema de base ecológica, e a restrição de recursos hídricos é um limitante na produção da cultura, pois qualquer estresse que as plantas sofram, podem acabar, fisiologicamente, facilitando a entrada de pragas e doenças, reduzindo drasticamente seu potencial produtivo.

Os desafios referentes à escassez de água devem ser enfrentados com gerenciamento do suprimento e da demanda, com a inclusão de novas fontes, como a exploração sustentada dos aquíferos subterrâneos, reflorestamento intensivo para proteger recargas e proteção e recuperação dos solos para melhor gestão da qualidade da água. O reuso da água deve ser um fator cada vez mais preponderante no século 21, podendo desempenhar papel econômico fundamental (FERNANDES, 2008).

Nesse sentido, foram levantados e discutidos com as comunidades os principais pontos para reduçãodos impactos da escassez hídrica, tais como: construção de barragens e cisternas, troca de sistema de irrigação por aspersão por gotejamento, utilização de cobertura morta entre outros. Essas técnicas, além de auxiliarem no acúmulo de água para posterior uso, contribuem para redução do seu desperdício além de contribuir para melhoria das qualidades 
físicas, químicas

Figura 1. Diálogo com agricultor familiar Fonte: Própria

e biológicas do solo.

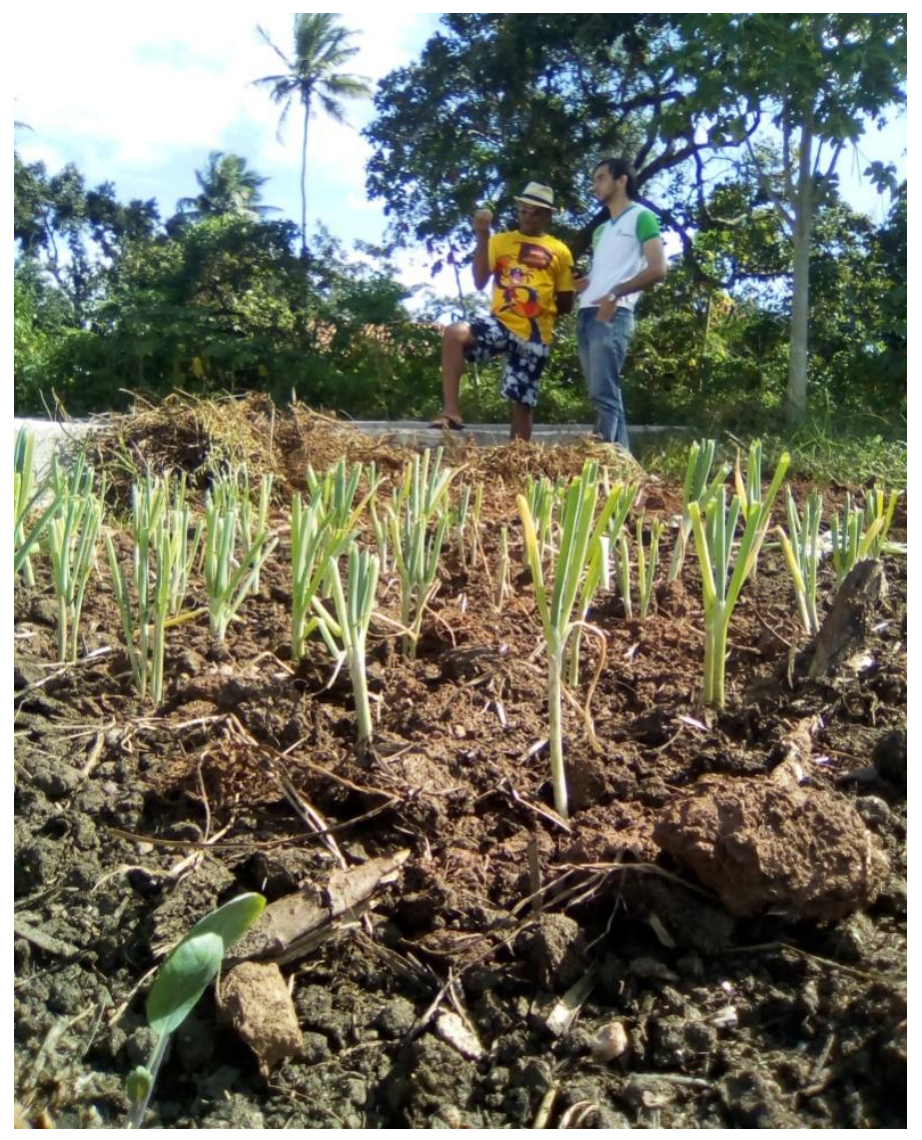

\section{Considerações}

O presente trabalho pôde contribuir de forma prática, através do compartilhamento das experiências entre os agricultores e estudantes, para a construção do conhecimento e melhoria da qualidade de vida nas comunidades rurais através das ações de ATER promovidas pelo IFPE em parceria com os movimentos sociais de agricultores familiares.

\section{Referências}

FERNANDES, A.L.T. Escassez e qualidade da água no século 21. Disponível em: $<$ https://www.feagri.unicamp.br/irrigacao/index.php?option=com_attachments\&task=downlo ad\&id=6> Acesso em: 07 Nov. 2018. 